TITLE:

\title{
Measurements of powder flow rate in gas-solids pipe flow based on the static electrification of particles
}

\section{$\operatorname{AUTHOR}(S)$ :}

Masuda, Hiroaki; Matsusaka, Shuji; Nagatani, Shinji

\section{CITATION:}

Masuda, Hiroaki ... [et al]. Measurements of powder flow rate in gas-solids pipe flow based on the static electrification of particles. Advanced Powder Technology 1994, 5(3): 241-254

\section{ISSUE DATE:}

1994

URL:

http://hdl.handle.net/2433/198909

\section{RIGHT:}

(C) Brill.; この論文は出版社版でありません。引用の際には出版社版を ご確認ご利用ください。; This is not the published version. Please cite only the published version. 


\title{
Measurements of Powder Flow Rate in Gas-Solids Pipe Flow \\ Based on the Static Electrification of Particles
}

Hiroaki MASUDA, Shuji MATSUSAKA and Shinji NAGATANI

Department of Chemical Engineering, Kyoto University Yoshida-Honmachi, Sakyo-ku, Kyoto 606-01, Japan

\begin{abstract}
A new measuring method of powder flow rate in gas-solids pipe flow was developed and investigated both theoretically and experimentally. The method is based on the static electrification of particles by their impaction on the inside wall. The powder flow rate was successfully calculated by use of the electric currents generated from the wall to the ground. It was found that the effect of initial charge of particles on the measurement could be eliminated by using two metallic pipes whose inner-surfaces were coated with different materials. It was also found that the powder flow rate and the mean particle charge could be measured simultaneously.
\end{abstract}

\section{NOMENCLATURE}

$a$

$b$

$c$

$D_{\mathrm{i}}$

$D_{\mathrm{p}}$

$d$

I

$I_{\mathrm{r}}$

$L$

$m$

$n(x)$ constant defined by Eq.(9) (-)

constant defined by Eq.(10) $\left(\mathrm{C} \mathrm{kg}^{-1}\right)$

constant defined by Eq.(16) $\left(\mathrm{kg} \mathrm{C}^{-1}\right)$

inside diameter of a pipe (m)

particle diameter $(\mathrm{m})$

constant defined by Eq.(17) $\quad\left(\mathrm{kg} \mathrm{C}^{-1}\right)$

electric current (A)

electric current for constant $\left(q / m_{\mathrm{p}}\right)_{0}$ (A)

length of a current detecting pipe (m)

powder to air mass flow ratio (-)

number of collisions of a particle (-) 
$n(\Delta x) \quad$ number of collisions of a particle between $x$ and $x+\Delta x(-)$

$n_{0} \quad$ relaxation number of collisions defined by Eq.(7) (-)

$q \quad$ particle charge (C)

$\left(q / m_{\mathrm{p}}\right)_{1},\left(q / m_{\mathrm{p}}\right)_{0} \quad$ initial charge per unit mass of particles $\left(\mathrm{C} \mathrm{kg}^{-1}\right)$

$\left(q / m_{\mathrm{p}}\right)_{\infty} \quad$ maximum possible charge per unit mass at $\mathrm{x}=\infty$ defined by Eq.(6) $\left(\mathrm{C} \mathrm{kg}^{-1}\right)$

$S \quad$ contact area between a particle and a wall $\left(\mathrm{m}^{2}\right)$

$\Delta t \quad$ duration of contact (s)

$\bar{u} \quad$ average air velocity $\left(\mathrm{m} \mathrm{s}^{-1}\right)$

V potential difference (V)

$V_{\mathrm{b}} \quad$ potential difference affected by space charge $(\mathrm{V})$

$V_{\mathrm{c}} \quad$ contact potential difference $(\mathrm{V})$

$V_{\mathrm{e}} \quad$ potential difference affected by image charge (V)

$\bar{v} \quad$ average particle velocity $\left(\mathrm{m} \mathrm{s}^{-1}\right)$

$x \quad$ effective flow length from inlet (m)

$\Delta x \quad$ length of a pipe (m)

$W_{\mathrm{p}} \quad$ powder flow rate $\left(\mathrm{kg} \mathrm{s}^{-1}\right)$

$z_{0}$

gap between contact bodies (m)

\section{Greek}

$\varepsilon_{0}$

$\rho$

$\rho_{\mathrm{p}}$

$\tau$

$\phi$

$\psi$

Subscripts

dielectric constant of air $\left(\mathrm{F} \mathrm{m}^{-1}\right)$

air density $\left(\mathrm{kg} \mathrm{m}^{-3}\right)$

particle density $\left(\mathrm{kg} \mathrm{m}^{-3}\right)$

relaxation time (s)

work function $(\mathrm{V})$

relative humidity (-)

0

first detecting pipe

1 


\section{INTRODUCTION}

On-line measurement of powder flow rate has been desired in order to control the powder handling processes. The methods, now available, are classified into three categories: (i) differential pressure methods, (ii) electrical methods, and (iii) statistical methods [1]. A powder flowmeter should have high accuracy and good repeatability without obstructing the aerosol flow. In particular, it is desired to be adapted to dilute suspension of fine particles. The electrical method based on the particle electrification is seemed to be suitable to such an aerosol process.

The electrical method is based on the fact that the charge transfer in dilute suspension flow is proportional to the powder flow rate [2]. However, the electrical method has some problems; the charge transfer depends both on the initial charge of particles and the electrostatic property of materials [2]. The effect of the initial charge on the charge transfer was confirmed experimentally with a larger particle of millimeter size [3]. In the present study, we have investigated the static electrification of fine aerosol particles and developed a new electrical method for measuring powder flow rate in gas-solids pipe flow.

\section{THEORY OF STATIC ELECTRIFICATION OF PARTICLES}

The electrification in aerosol processes is caused by contact or impact between particles and the inside wall of equipment. If an aerosol particle strikes the metallic wall, the particle and the wall acquire electric charges of opposite polarity but equal amount. The driving force of the charge transfer is the potential difference $V$ between contact bodies, which depends on the contact potential difference $V_{\mathrm{c}}$, image charge effect $V_{\mathrm{e}}$, and space charge effect $V_{b}[4]$;

$$
V=V_{\mathrm{c}^{-}}-V_{\mathrm{e}}-V_{\mathrm{b}}
$$

Assuming the spherical particle of diameter $D_{\mathrm{p}}$, the image charge effect $V_{\mathrm{e}}$ in Eq.(1) is given by $[2,4]$ : 


$$
V_{\mathrm{e}}=\frac{2 q z_{0}}{\pi \varepsilon_{0} D_{\mathrm{p}}^{2}}
$$

where $q$ is the charge of the particle, $z_{0}$ the gap between the contact bodies, and $\varepsilon_{0}$ the dielectric constant of air. Further, assuming that aerosol particles are uniformly distributed in the pipe, the space charge effect $V_{\mathrm{b}}$ in Eq. (1) is obtained as [2, 4]:

$$
V_{\mathrm{b}}=\frac{q D_{\mathrm{i}} z_{0} m \rho \bar{u}}{4 m_{\mathrm{p}} \varepsilon_{0} \bar{v}}
$$

where $D_{\mathrm{i}}$ is the inside diameter of the pipe, $m$ the particle to air mass flow ratio, $\rho$ is the air density, $\bar{u}$ the average air velocity, and $\bar{v}$ the average particle velocity.

Applying a condenser model to the particle electrification in pipe flow, the charge transferred is represented by the following differential equation [2]:

$$
\frac{\mathrm{d} q}{\mathrm{~d} n(x)}=\varepsilon_{0} \frac{S V}{z_{0}}\left(1-\mathrm{e}^{-\Delta t / \tau}\right)
$$

where, $n(x)$ is the cumulative number of collisions, $S$ the contact area between the particle and the wall, $\Delta t$ the duration of contact, and $\tau$ is the relaxation time. Charge transferred from the particle to the grounded metallic pipe is measured as an electric current. The electric current $I$ generated from a pipe of length of $\Delta x$ and effective flow length $x$ can be derived from Eq. (4) as follows [2]:

$$
\begin{aligned}
I & =W_{\mathrm{p}}\left\{\left(\frac{q}{m_{\mathrm{p}}}\right)_{0}-\left(\frac{q}{m_{\mathrm{p}}}\right)_{\infty}\right\}\left\{\mathrm{e}^{-n(x) / n_{0}}\right\}\left\{1-\mathrm{e}^{-n(\Delta x) / n_{0}}\right\} \\
& \cong W_{\mathrm{p}}\left\{\left(\frac{q}{m_{\mathrm{p}}}\right)_{0}-\left(\frac{q}{m_{\mathrm{p}}}\right)_{\infty}\right\} \frac{n(\Delta x)}{n_{0}}
\end{aligned}
$$

where

$$
\left(\frac{q}{m_{\mathrm{p}}}\right)_{\infty}=\frac{3 \varepsilon_{0} V_{\mathrm{c}}}{\rho_{\mathrm{p}} D_{\mathrm{p}} z_{0}\left(1+\frac{3}{4} m \frac{\rho D \bar{u}}{\rho_{\mathrm{p}} D_{\mathrm{p}} \bar{v}}\right)}
$$

and 


$$
\begin{aligned}
n_{0}= & \frac{\pi D_{\mathrm{p}}^{2}}{2 S\left(1+\frac{3}{4} m \frac{\rho D \bar{u}}{\rho_{\mathrm{p}} D_{\mathrm{p}} \bar{v}}\right)\left(1-\mathrm{e}^{-\Delta t / \tau}\right)} \\
& \cong \frac{\pi D_{\mathrm{p}}^{2}}{2 S\left(1+\frac{3}{4} m \frac{\rho D \bar{u}}{\rho_{\mathrm{p}} D_{\mathrm{p}} \bar{v}}\right) \frac{\Delta t}{\tau}}
\end{aligned}
$$

$W_{\mathrm{p}}$ is the powder flow rate, $\left(q / m_{\mathrm{p}}\right)_{0}$ the initial charge per unit mass of particles, $\left(q / m_{\mathrm{p}}\right)_{\infty}$ the maximum possible charge per unit mass of particles at $x=\infty, n_{0}$ the relaxation number of collisions of a particle, and $\rho_{\mathrm{p}}$ the particle density.

For dilute aerosol flow where the space charge effect is negligible, the following equation is derived from Eqs. (5)-(7):

$$
\frac{I}{W_{\mathrm{p}}}=a\left(\frac{q}{m_{\mathrm{p}}}\right)_{0}+b
$$

where

$$
a=\frac{2 n(\Delta x) S \Delta t}{\pi D_{\mathrm{p}}{ }^{2} \tau}
$$

and

$$
b=-\frac{6 \varepsilon_{0} V_{\mathrm{c}} n(\Delta x) S \Delta t}{\pi D_{\mathrm{p}}^{3} \rho_{\mathrm{p}} z_{0} \tau}
$$

\section{EXPERIMENTAL APPARATUS AND PROCEDURES}

Fig. 1 shows the experimental apparatus for studying the electrification of particles in gas-solids pipe flow. A table feeder (Sankyo Pio-tech Co., Ltd., MFOV-1) is used in order to get a constant flow-rate of fine powder. A narrow suction nozzle (outside diameter is $1 \mathrm{~mm}$ ) was utilized to cut off a thin powder layer from the rotating table surface and a small amount of powder was evacuated continuously through the nozzle. The powder feed rate was adjusted by the rotating 
speed of the table. Then the powder was dispersed into an air stream through an ejector (Nihon Pisco Co., Ltd., VRL 50-080108) and fed into a current detector (see Table 1). Current data obtained by an electrometer were automatically sampled into a computer (10 data per second). Particle charges before and after the current detector were also measured by use of a Faraday cage. Test powders and experimental conditions are shown in Table 2.

\section{RESULTS AND DISCUSSION}

\subsection{Particle electrification in gas-solids pipe flow}

Fig. 2 shows the particle size distributions for aerosol particles before and after the current detecting pipe ( $0.8 \mathrm{~m}$ long), and particles fully dispersed in aqueous solution. The aerosol particle size distributions were measured with a cascade impactor (Andersen sampler), while the particles in aqueous solution were measured by a sedimentation method (Sedigraph 5000). It was shown that the powder was fully dispersed by the ejector, and little agglomerations occur in the current detecting pipe as these three particle size distributions were almost the same. Thus, it is supposed that each primary particle impacts to the inside wall of the current detecting pipe.

Fig. 3(a) shows currents generated from the detecting pipe as a function of time elapsed. The background noise before powder feeding is small enough for the measurements. The generated current is almost constant $(I=2.3 \mathrm{nA})$ as long as the powder flow rate is kept constant $\left(W_{\mathrm{p}}=\right.$ $7.0 \times 10^{-7} \mathrm{~kg} \mathrm{~s}^{-1}$. Fig. 3(b) shows cumulative charges both at the inlet and the outlet of the current detecting pipe as a function of time elapsed. The cumulative charge is proportional to the time elapsed showing the average charge of particles is nearly constant and also the powder flow rate is. The values of the charge per unit mass of particles at the inlet and the outlet are $\left(\mathrm{q} / \mathrm{m}_{\mathrm{p}}\right)_{0}=3.9 \times 10^{-3}$ $\mathrm{C} \mathrm{kg}^{-1}$ and $\left(\mathrm{q} / \mathrm{m}_{\mathrm{p}}\right)_{1}=0.6 \times 10^{-3} \mathrm{C} \mathrm{kg}^{-1}$, respectively. Namely, the particles give a positive charge to the current detecting pipe $\left(\left(q / m_{\mathrm{p}}\right)_{0}-\left(q / m_{\mathrm{p}}\right)_{1}=3.3 \times 10^{-3} \mathrm{C} \mathrm{kg}^{-1}\right)$. This value agrees with that of the current generated per unit powder flow rate $\left(I / W_{\mathrm{p}}=3.3 \times 10^{-3} \mathrm{C} \mathrm{kg}^{-1}\right)$. Fig. 4 shows the data of the 
relation between $I / W_{\mathrm{p}}$ and $\left(q / m_{\mathrm{p}}\right)_{0}-\left(q / m_{\mathrm{p}}\right)_{1} . I / W_{\mathrm{p}}$ agreed with $\left(q / m_{\mathrm{p}}\right)_{0}-\left(q / m_{\mathrm{p}}\right)_{1}$ within $10 \%$ error in the detecting system.

\subsection{Effect of initial charge on the current generated}

Experimental values of current $I$ as a function of powder flow rate $W_{\mathrm{p}}$ are shown in Fig. 5. The data are widely scattered, though $I$ tends to increase with increasing $W_{\mathrm{p}}$. The scatter can be attributed to the variation in the initial charge of particles $\left(1.0 \times 10^{-3}<\left(q / m_{\mathrm{p}}\right)_{0}<4.9 \times 10^{-3} \mathrm{C} \mathrm{kg}^{-1}\right)$ as described by Eq. (8). The experimental relation between $I / W_{\mathrm{p}}$ and $\left(q / m_{\mathrm{p}}\right)_{0}$ is shown in Fig. 6 , where the data are represented by the following equation with the standard deviation of $3.0 \times 10^{-4} \mathrm{C} \mathrm{kg}^{-1}$.

$$
\frac{I}{W_{\mathrm{p}}}=0.851\left(\frac{q}{m_{\mathrm{p}}}\right)_{0}+3.3 \times 10^{-6}
$$

By use of Eq. (11), $I$ can be transformed into $I_{\mathrm{r}}$, the current expected when the initial charge $\left(q / m_{\mathrm{p}}\right)_{0}$ is kept constant at $3.0 \times 10^{-3} \mathrm{C} \mathrm{kg}^{-1}$. Fig. 7 shows $I_{\mathrm{r}}$ as a function of the powder flow rate. As expected, $I_{\mathrm{r}}$ is proportional to $W_{\mathrm{p}}$ and the scatter of the values is much smaller than that in Fig. 5 . Therefore, the electrical method seems to be well applied to the measurement of powder flow rate if the effect of the initial charge is eliminated.

\subsection{A new electrical method for the measurement of powder flow rate}

The use of a Faraday cage in an on-line system is undesirable and we present a new electrical method where the effect of the initial charge can be automatically eliminated without using a Faraday cage. The new electric current detecting system is shown in Fig. 8. The current detector has two metallic pipes with insulators for electrical isolation. The insulator between the pipes is very small in order to reduce the electrostatic noise, and the distance between the two pipes is less than 1 $\mathrm{mm}$. The current generated from each pipe is alternately sampled into a computer with a scanner controlled by the same computer. 
We discuss here the principle of this system. As described in Eq. (8), the current generated per unit powder flow rate from the first pipe and the second pipe $\left(I_{0} / W_{\mathrm{p}}\right.$ and $\left.I_{1} / W_{\mathrm{p}}\right)$ are respectively given by the following equations:

$$
\begin{aligned}
& \frac{I_{0}}{W_{\mathrm{p}}}=a_{0}\left(\frac{q}{m_{\mathrm{p}}}\right)_{0}+b_{0} \\
& \frac{I_{1}}{W_{\mathrm{p}}}=a_{1}\left(\frac{q}{m_{\mathrm{p}}}\right)_{1}+b_{1}
\end{aligned}
$$

where $\left(q / m_{\mathrm{p}}\right)_{0}$ and $\left(q / m_{\mathrm{p}}\right)_{1}$ are the initial charge per unit mass at the inlet of the first pipe and the second pipe, respectively. Since the charge at the outlet of the first pipe should be equal to the charge at the inlet of the second pipe, the following equation is obtained:

$$
\left(\frac{q}{m_{\mathrm{p}}}\right)_{0}-\left(\frac{q}{m_{\mathrm{p}}}\right)_{1}=\frac{I_{0}}{W_{\mathrm{p}}}
$$

From Eqs. (12) - (14), powder flow rate $W_{\mathrm{p}}$ is represented as follows:

$$
W_{\mathrm{p}}=c I_{0}+d I_{1}
$$

where

$$
\begin{aligned}
& c=\frac{\left(a_{0}-1\right) a_{1}}{a_{0} b_{1}-a_{1} b_{0}} \\
& d=\frac{a_{0}}{a_{0} b_{1}-a_{1} b_{0}}
\end{aligned}
$$

The constants $c$ and $d$, which depend on the property of particle electrification in the two pipes, can be obtained experimentally beforehand. Therefore, powder flow rate $W_{\mathrm{p}}$ can be calculated from Eq. (15) based on the measured values $I_{0}$ and $I_{1}$. In Eqs. (16) and (17), the following equation should be satisfied.

$$
\frac{b_{0}}{a_{0}} \neq \frac{b_{1}}{a_{1}}
$$

From Eqs. (9) and (10), b/a is represented by the following equation: 


$$
\frac{b}{a}=-\frac{3 \varepsilon_{0} V_{\mathrm{c}}}{\rho_{\mathrm{p}} z_{0} D_{\mathrm{p}}}
$$

Each factor on the right-hand side of Eq. (19) is related to both electrical and physical properties. From Eq. (18), inside surface materials of the two pipes should be different each other. Further, it is desired that $b_{0} / a_{0}$ is greatly different from $b_{1} / a_{1}$ in order to reduce the experimental error.

From Eqs. (12), (15)-(17), initial charge per unit mass $\left(q / m_{\mathrm{p}}\right)_{0}$ is also derived as follows:

$$
\left(\frac{q}{m_{\mathrm{p}}}\right)_{0}=\frac{\left(b_{1}-a_{1} b_{0}\right) I_{0}-b_{0} I_{1}}{a_{1}\left(a_{0}-1\right) I_{0}+a_{0} I_{1}}
$$

Eq. (20) describes that $\left(q / m_{\mathrm{p}}\right)_{0}$ can be obtained simultaneously in this measuring system.

In the experiment, we used two stainless pipes $\left(D_{\mathrm{i}}=0.006 \mathrm{~m}, L=0.07 \mathrm{~m}\right)$ : one is coated with Titanium nitride (TiN: work function $\phi=2.92 \mathrm{eV}$ [5]) and the other is coated with platinum (Pt: $\phi=$ $5.64 \mathrm{eV}$ [5]). Fig. 9 shows the currents generated by fly-ash No.10 as a function of time elapsed. The currents generated both from the TiN coated pipe and from the Pt coated pipe are almost constant after a few minutes elapsed, though periodic fluctuations are found. The time delay of the generated currents occurred in the first measurement [6], and the periodic fluctuations were found to be caused by the variation of powder flow rate according to the rotation of the table feeder: 3.4 rpm in Fig. 9 (a) and 1.7 rpm in Fig. 9 (b). The facts also confirm that the measuring system has high sensitivity in detecting the small variation of powder flow rate. Fig. 10 shows the alternately measured currents from the TiN coated pipe and the Pt coated pipe. When current detected from one pipe is in measurement, the other pipe is grounded as shown in Fig. 8. The switching period is set at $1 \mathrm{~s}$ and current generated in the first period of $0.4 \mathrm{~s}$ is discarded so as to avoid the switching noise. The sign of the current generated from the TiN coated pipe is different from that of Pt coated pipe owing to the electrostatic property of the materials.

Fig. 11 shows the current generated per unit powder flow rate $I / W_{\mathrm{p}}$ as a function of initial charge $\left(q / m_{\mathrm{p}}\right)$ for TiN coated pipe and Pt coated pipe. In both cases, $I / W_{\mathrm{p}}$ are proportional to $\left(q / m_{\mathrm{p}}\right)$ and are respectively represented by the following equations:

$$
\frac{I}{W_{\mathrm{p}}}=0.0882\left(\frac{q}{m_{\mathrm{p}}}\right)_{0}+5.2 \times 10^{-5} \quad: \text { TiN coated pipe }
$$




$$
\frac{I}{W_{\mathrm{p}}}=0.219\left(\frac{q}{m_{\mathrm{p}}}\right)_{1}-4.48 \times 10^{-4} \quad: \text { Pt coated pipe }
$$

The TiN coated pipe was utilized as the first detecting pipe and the Pt coated one as the second in the experiments. Eliminating $\left(q / m_{\mathrm{p}}\right)_{0}$ and $\left(q / m_{\mathrm{p}}\right)_{1}$ from Eqs. (15)-(17), (21), and (22), powder flow rate $W_{\mathrm{p}}$ is represented as follows:

$$
W_{\mathrm{p}}=3.91 \times 10^{3} I_{0}-1.73 \times 10^{3} I_{1}
$$

The calculated powder flow rates by use of Eq. (23), and the corresponding measured values obtained through a direct weighing are compared in Fig. 12 for fly-ash particles. The relative error between the calculated and the measured values are within $10 \%$. On the other hand, the results for alumina powder are shown in Fig. 13. The polarity of the initial charge $\left(q / m_{\mathrm{p}}\right)_{0}$ of the alumina powder was negative while the fly-ash positive. The relative error of the measurement is also within $10 \%$ irrespective of the polarity. These experimental results show the possibility of on-line measurement of powder flow rate in gas-solid suspensions.

The on-line measurement was also applied to get initial charge per unit mass $\left(q / m_{\mathrm{p}}\right)_{0}$ from the results of alumina powder where $\left(q / m_{\mathrm{p}}\right)_{0}$ are widely distributed $\left(-0.005\right.$ to $\left.-0.014 \mathrm{C} \mathrm{kg}^{-1}\right)$. From Eq. (20), $\left(q / m_{\mathrm{p}}\right)_{0}$ was obtained simultaneously and shown in Fig. 14. It was found that the calculated values of $\left(q / m_{\mathrm{p}}\right)_{0}$ agreed with the measured values within the standard deviation of $1.4 \times 10^{-3} \mathrm{C} \mathrm{kg}^{-1}$. Therefore, this system is also applicable to the on-line measurement of the particle charge.

\section{CONCLUSION}

The on-line measurements of powder flow rate in gas-solids pipe flow were carried out by a new electrical method. The results obtained are summarized as follows:

(1) Charge transferred per unit mass of particles is equal to the current generated per unit powder flow rate.

(2) Current generated per unit powder flow rate is proportional to the initial charge per unit mass of particles. 
(3) Powder flow rate and particle charge can be simultaneously measured through on-line calculation based on the currents generated from two metallic pipes whose inner surface are coated with different materials. The relative error in the measurements is within $10 \%$.

\section{REFERENCES}

1. H. Masuda and T. Wakamatsu, Concentration and flow rate measurement. In: Powder Technology Handbook, K. Iinoya, K. Gotoh and K. Higashitani (eds.). New York : Marcel Dekker, 1991, 743-756.

2. H. Masuda, T. Komatsu and K. Iinoya, The static electrification of particles in gas-solids pipe flow. AIChE J., 22, pp. 558-564, 1976.

3. H. Yamamoto and B. Scarlett, Triboelectric charging of polymer particles by impact. Particle Characterization, 3, 117-121, 1986.

4. B. N. Cole, M. R. Baum and F. R. Mobbs, An investigation of electrostatic charging effects in high-speed gas-solids pipe flows. Proc. Instn. Mech. Engrs., 184, Pt3C 77, 1969-1970.

5. Nippon Kagakkai (ed.), Kagaku Benran. 3rd, Maruzen, 1984, II493-494 (in Japanese).

6. H.Masuda, T.Komatsu, N. Mitsui and K.Iinoya, Electrification of gas-solid suspensions flowing in steel and insulating-coated pipes. J. Electrostatics, 2, 341, 1976/1977. 
Compressor

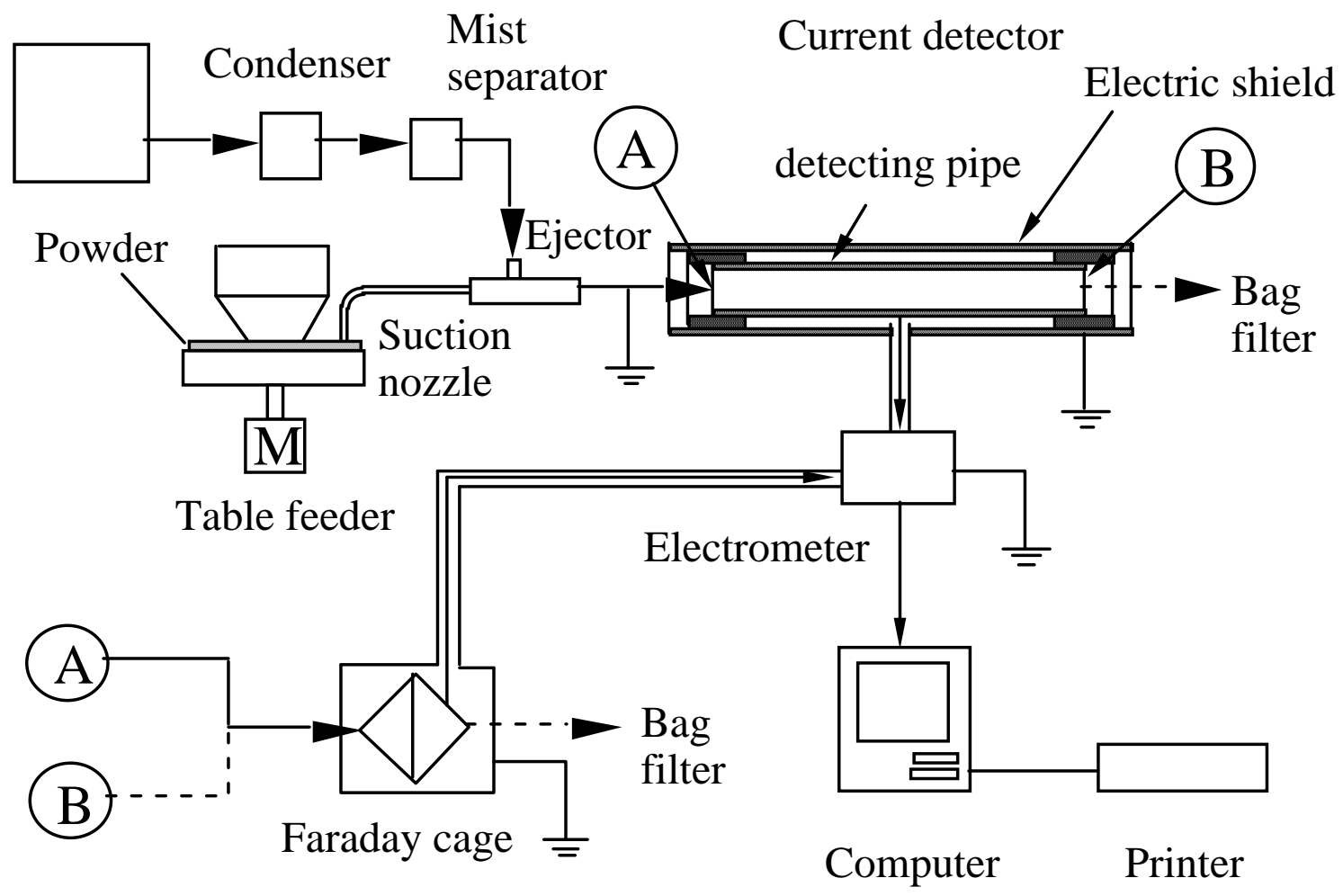

Figure 1. Experimental apparatus 

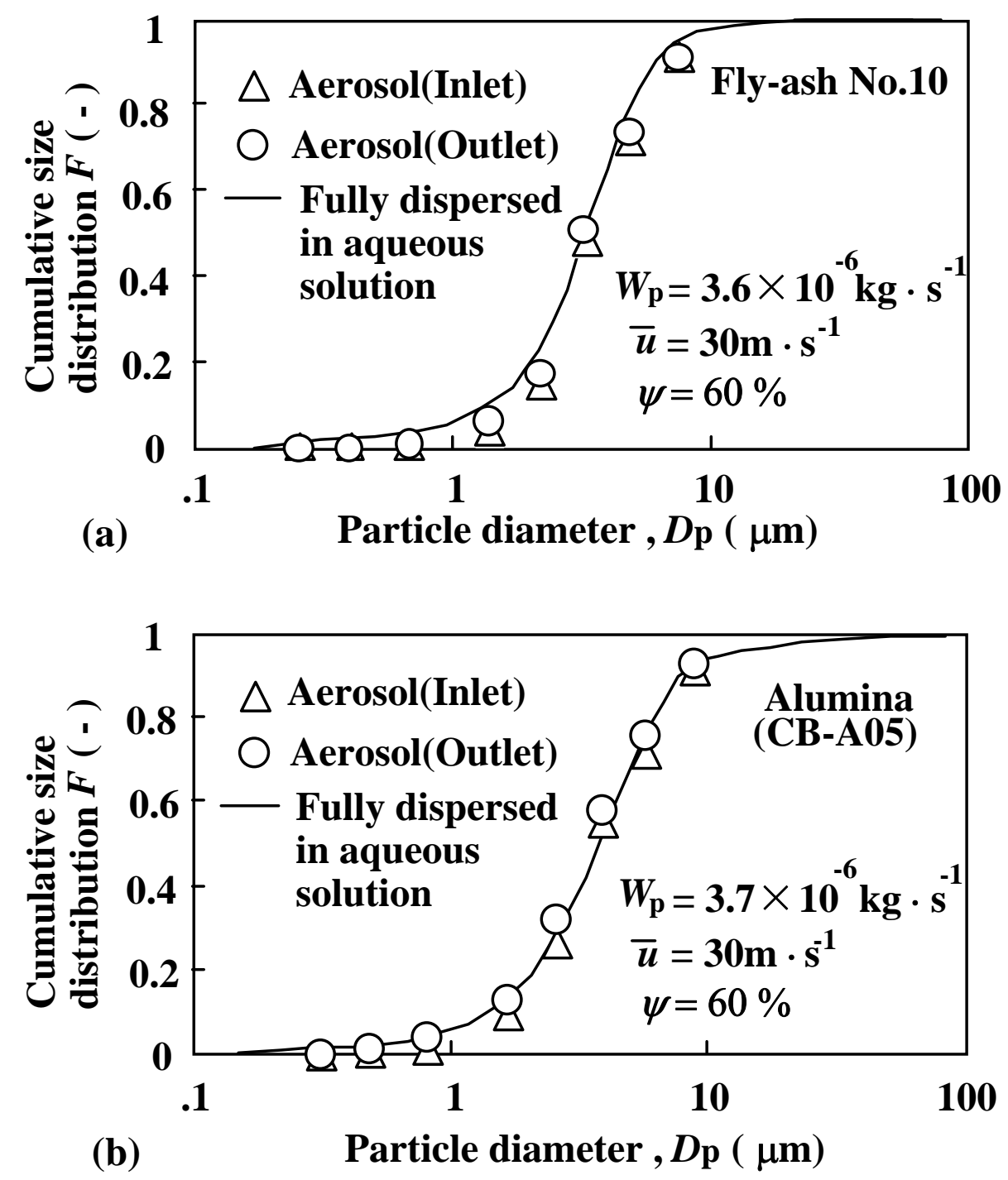

Figure 2. Particle size distribution (aerosol ; measured with cascade impactor, particles in aqueous solution ; measured with Sedi Graph-5000) 

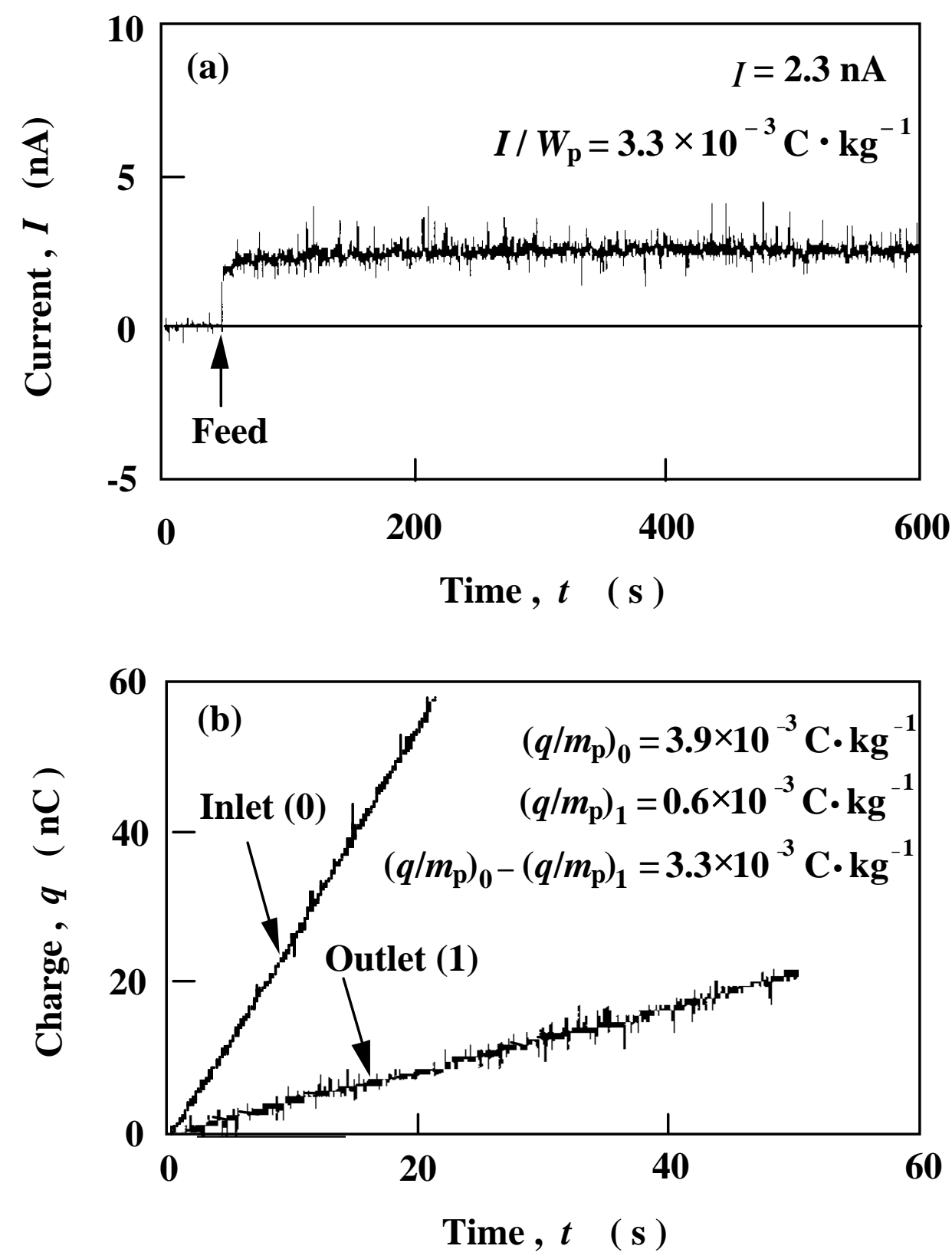

Figure 3. (a) Currents generated from detecting pipe

(b) Cumulative charge measured by Faraday cage (powder ; fly-ash No.10, detecting pipe ; stainless,

$$
\begin{aligned}
& D_{\mathrm{i}}=0.006 \mathrm{~m}, L=0.8 \mathrm{~m}, W_{\mathrm{p}}=7.0 \times 10^{-7} \mathrm{~kg} \cdot \mathrm{s}^{-1}, \\
& \left.\bar{u}=30 \mathrm{~m} \cdot \mathrm{s}^{-1}, \psi=45 \%\right)
\end{aligned}
$$




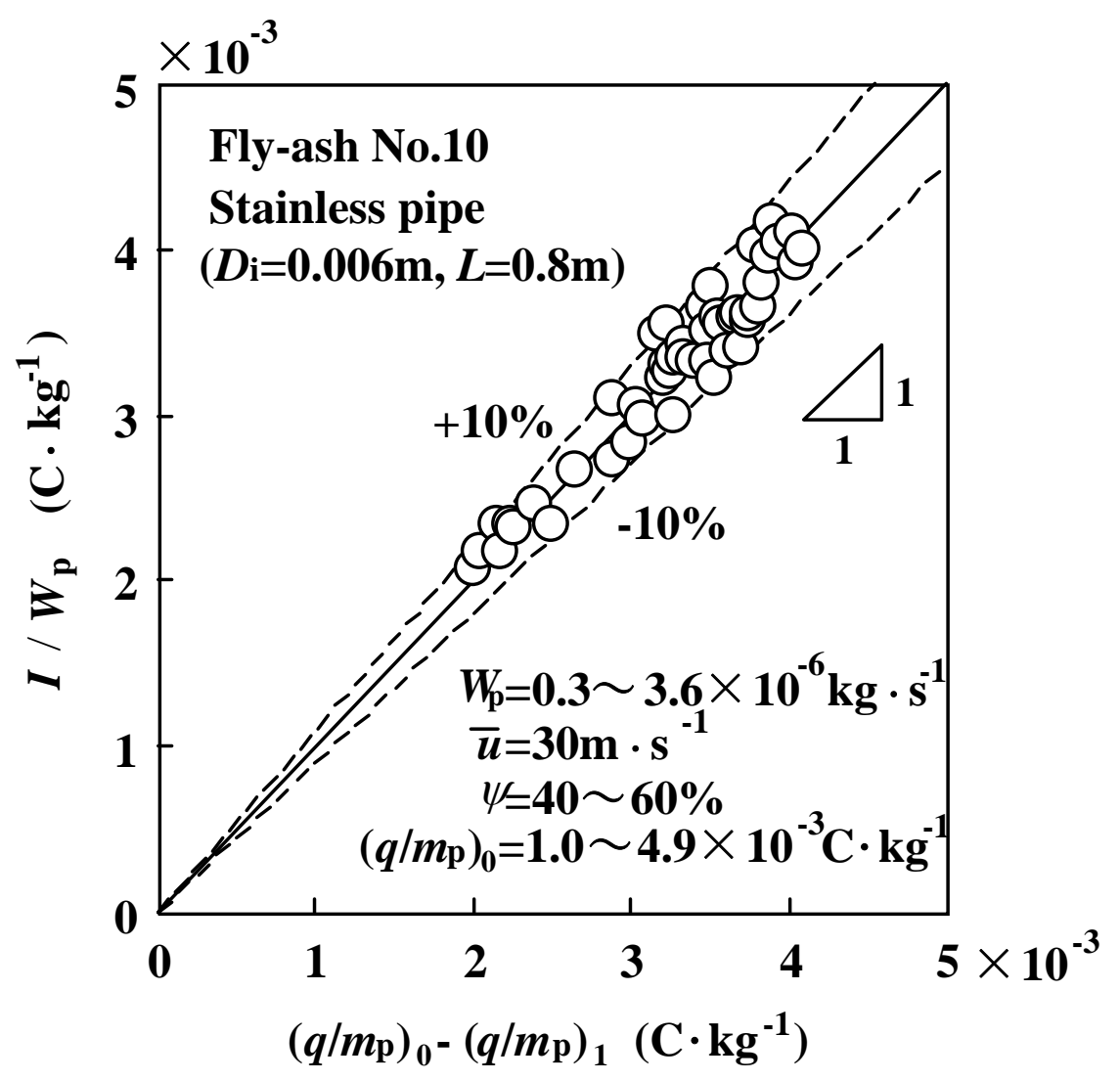

Figure 4. Charge transferred from particles to the current detecting pipe 


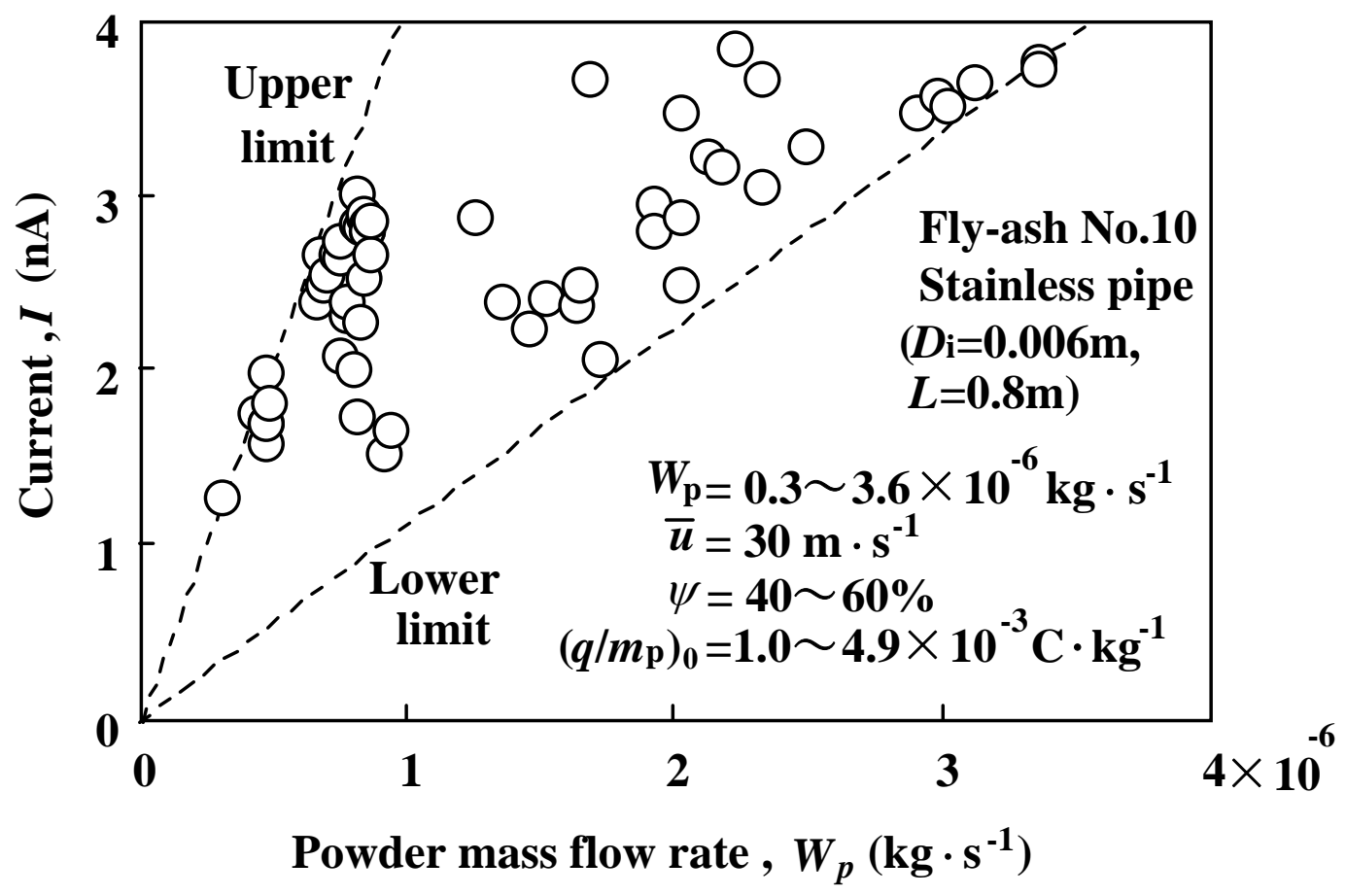

Figure 5. Relation between current $\boldsymbol{I}$ and powder flow rate $\boldsymbol{W}_{\mathbf{p}}$ (initial charge of particles are scattered) 


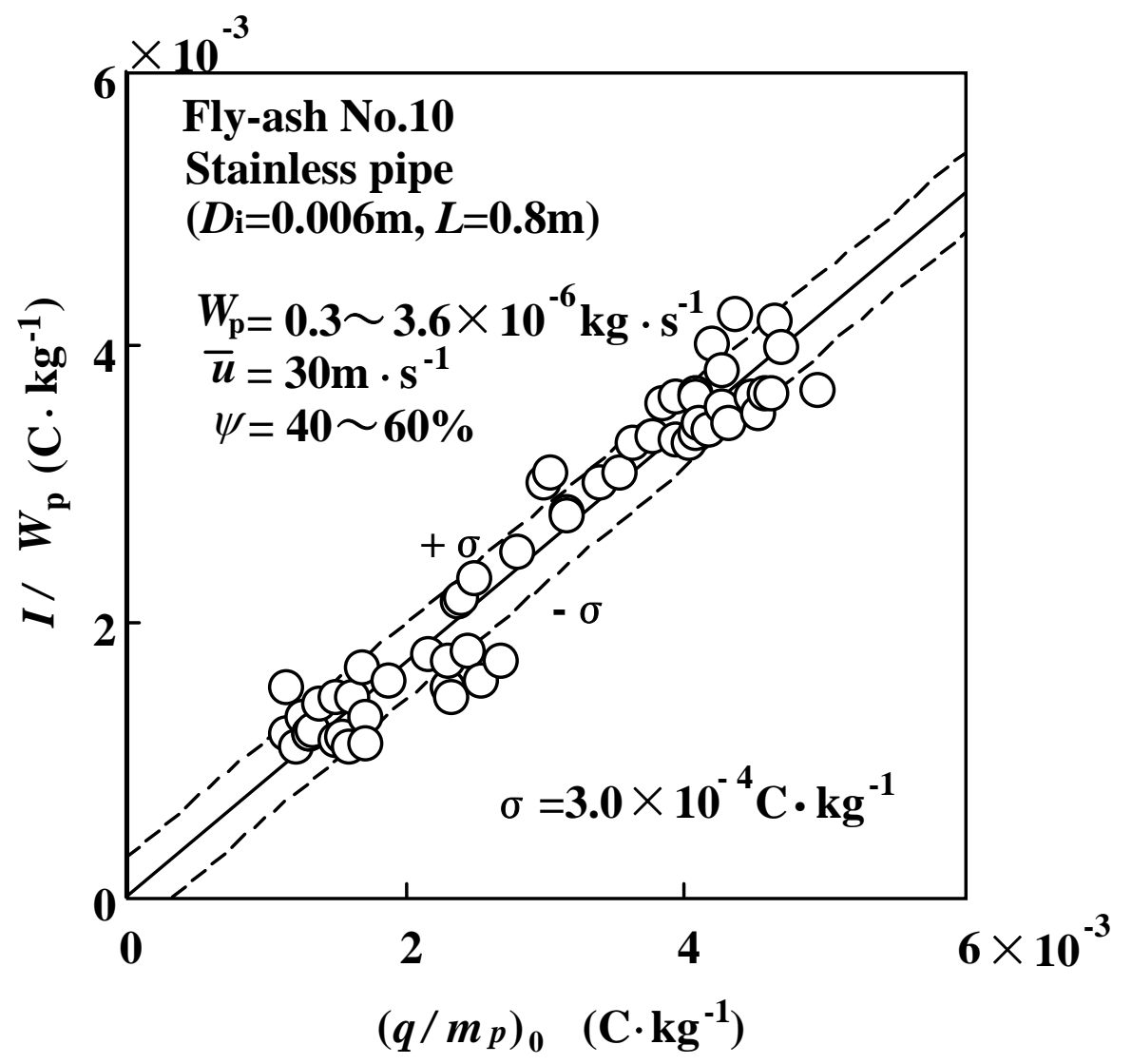

Figure 6. Effect of initial charge of particles $\boldsymbol{q}_{\mathbf{0}} / \boldsymbol{m}_{\mathbf{p}}$ on the current generated by unit mass flow rate of powder $\mathbf{I} / \boldsymbol{W}_{\mathbf{p}}$ 


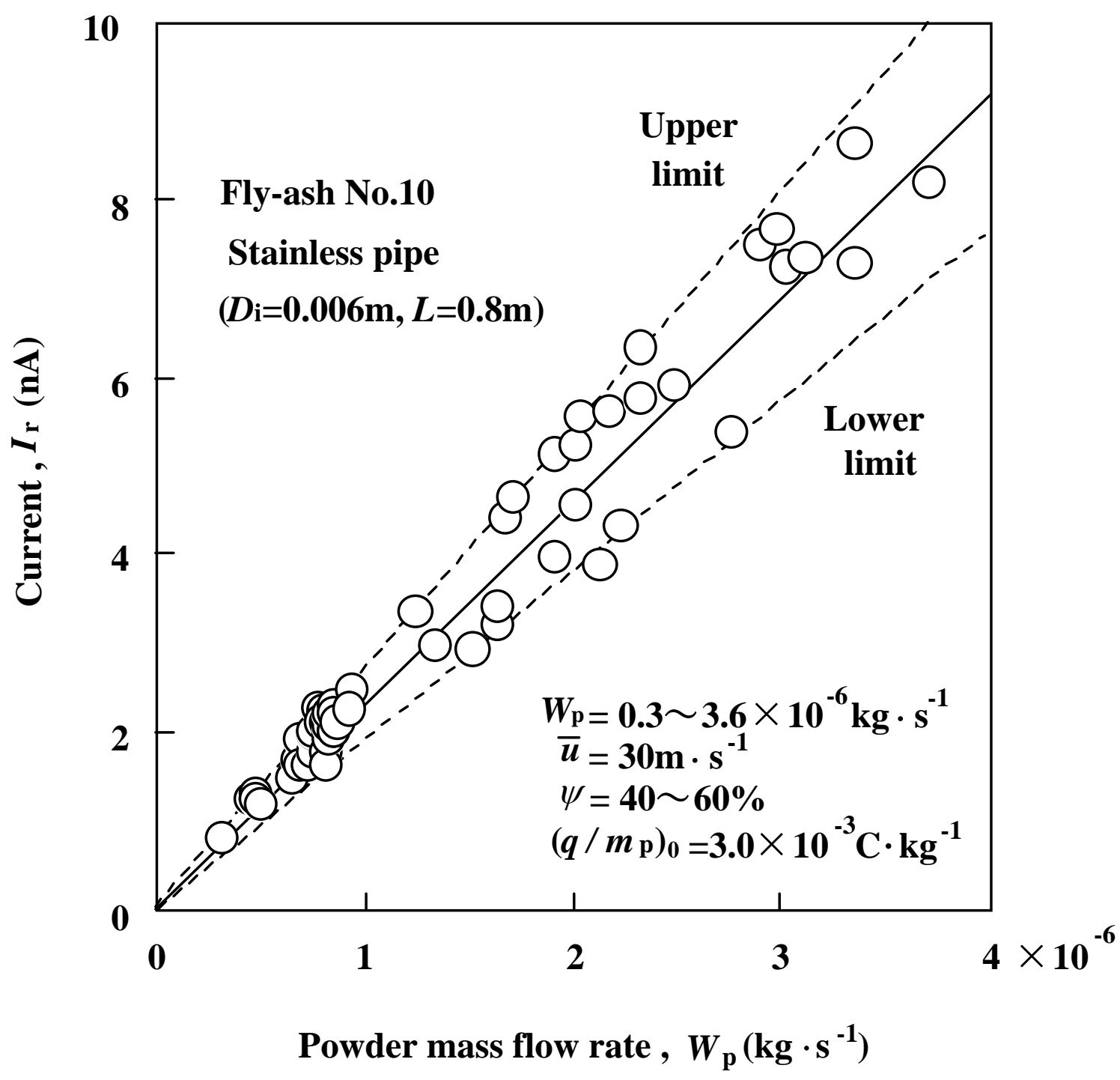

Figure 7. Relation between current $\boldsymbol{I}_{\mathbf{r}}$ and powder flow rate $\boldsymbol{W}_{\mathbf{p}}$ 


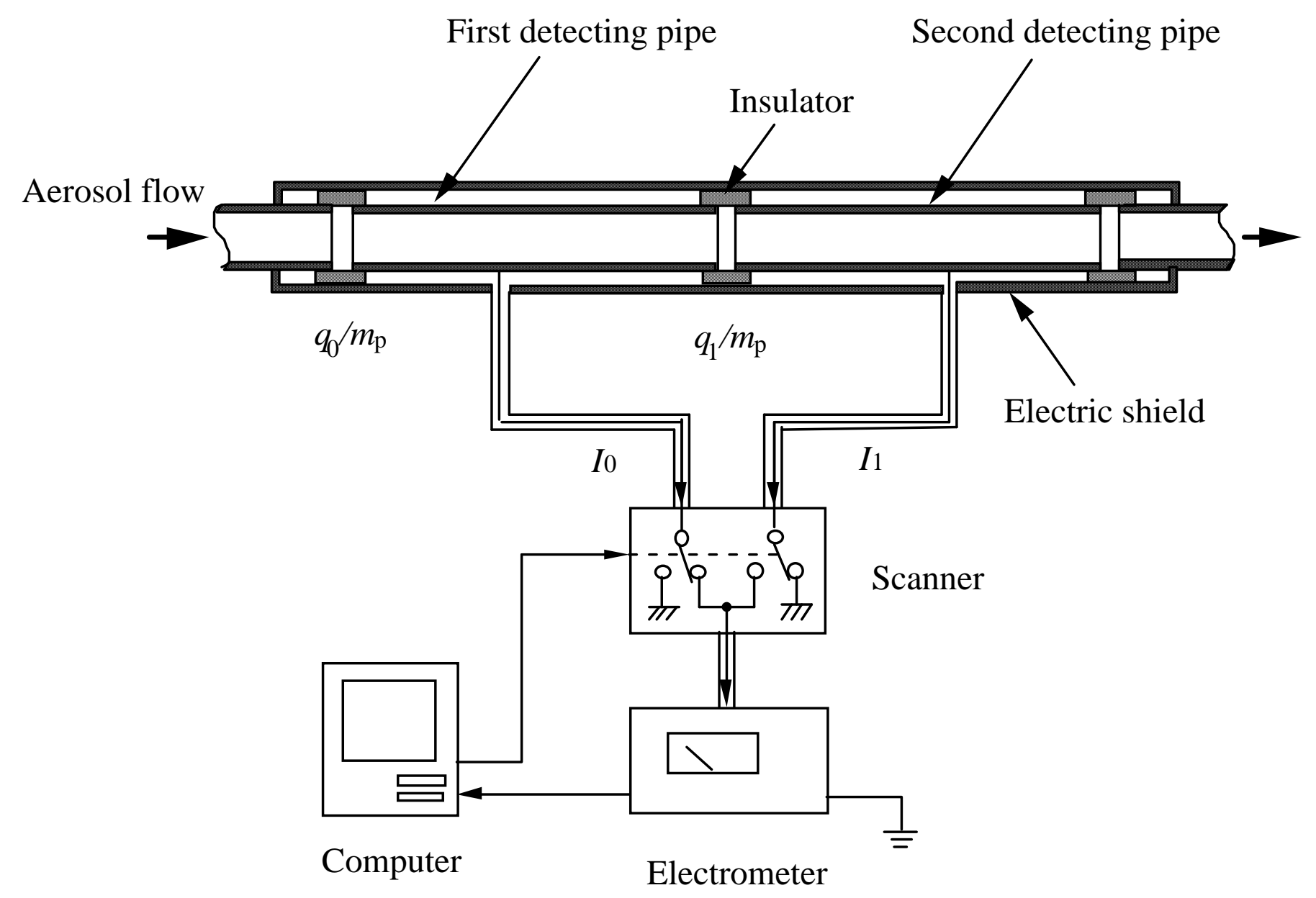

Figure 8. Details of a new electric current detecting system 

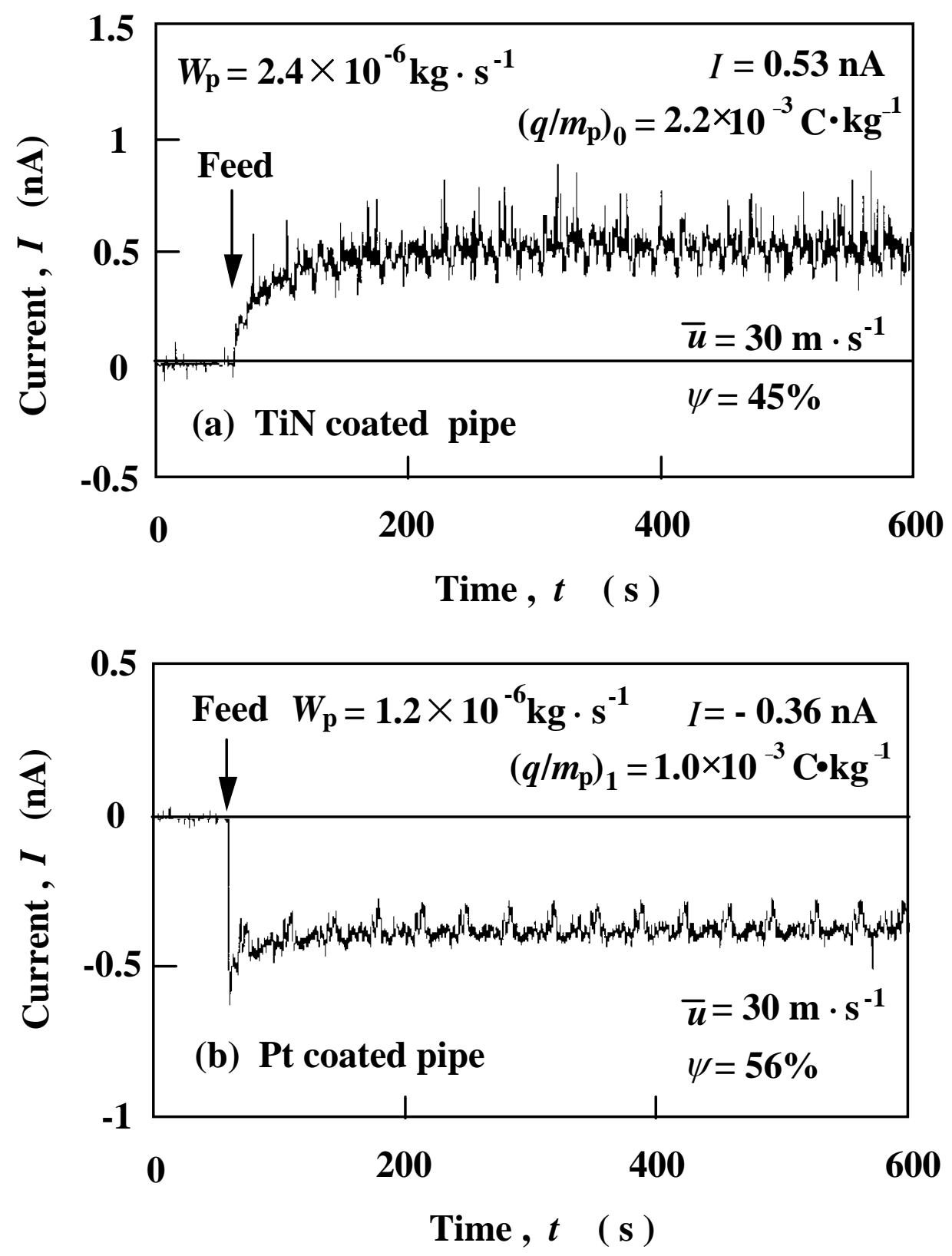

Figure 9. Currents as a function of time elapsed (fly-ash No.10) 


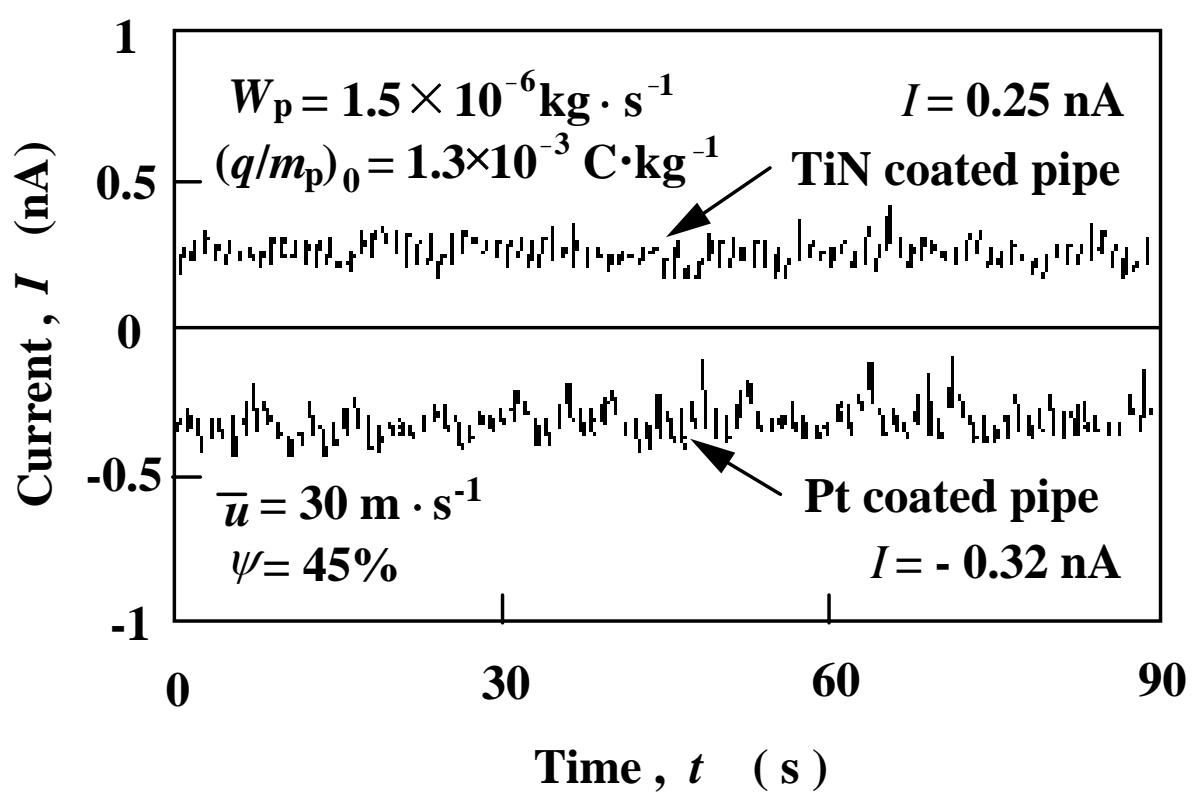

Figure 10. Currents detected through a scanner ( fly-ash No.10 ) 


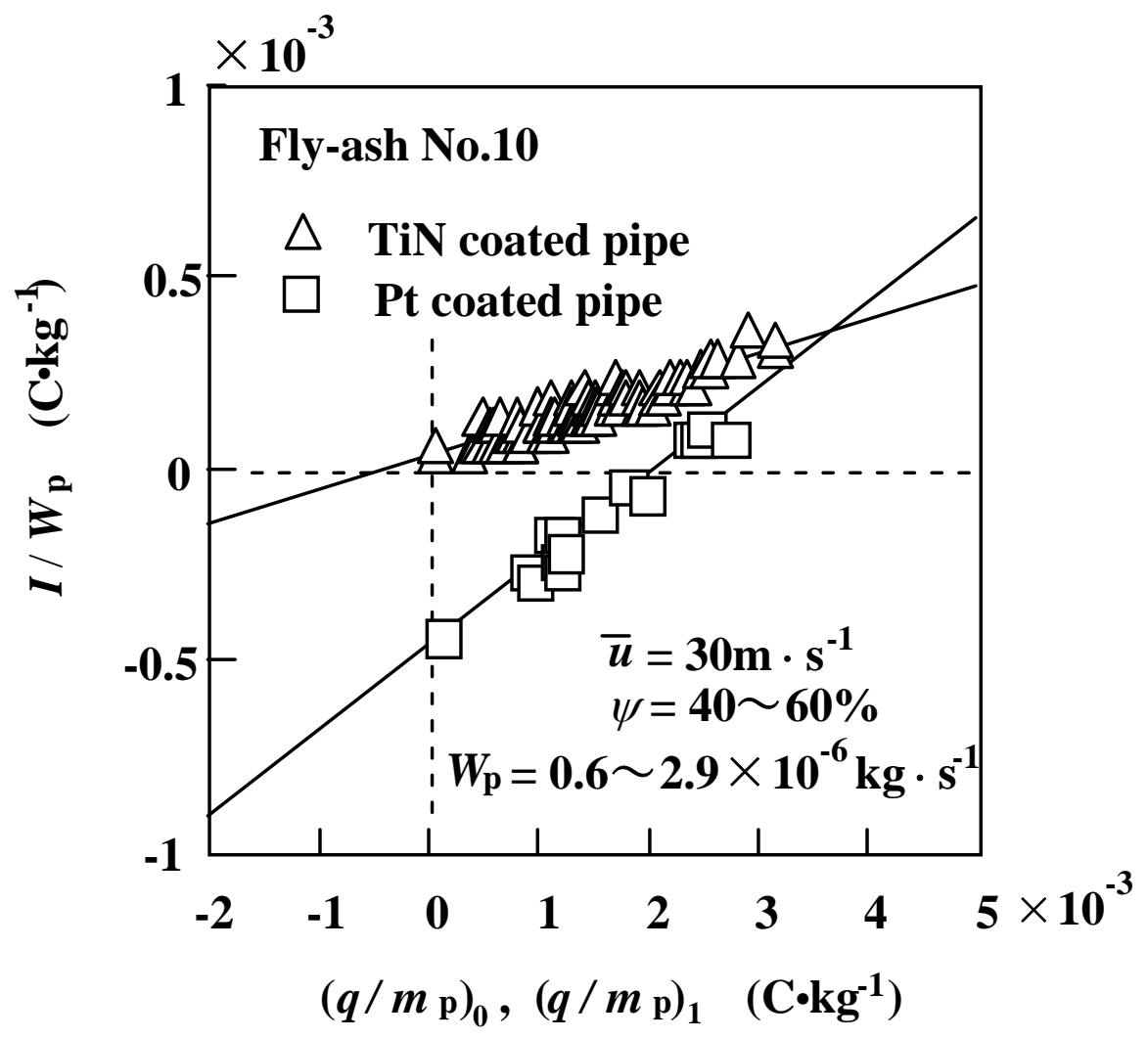

Figure 11. Relation between $\boldsymbol{I} / \boldsymbol{W}_{\mathbf{p}}$ and $\boldsymbol{q} / \boldsymbol{m}_{\mathbf{p}}$ for different detecting pipes 


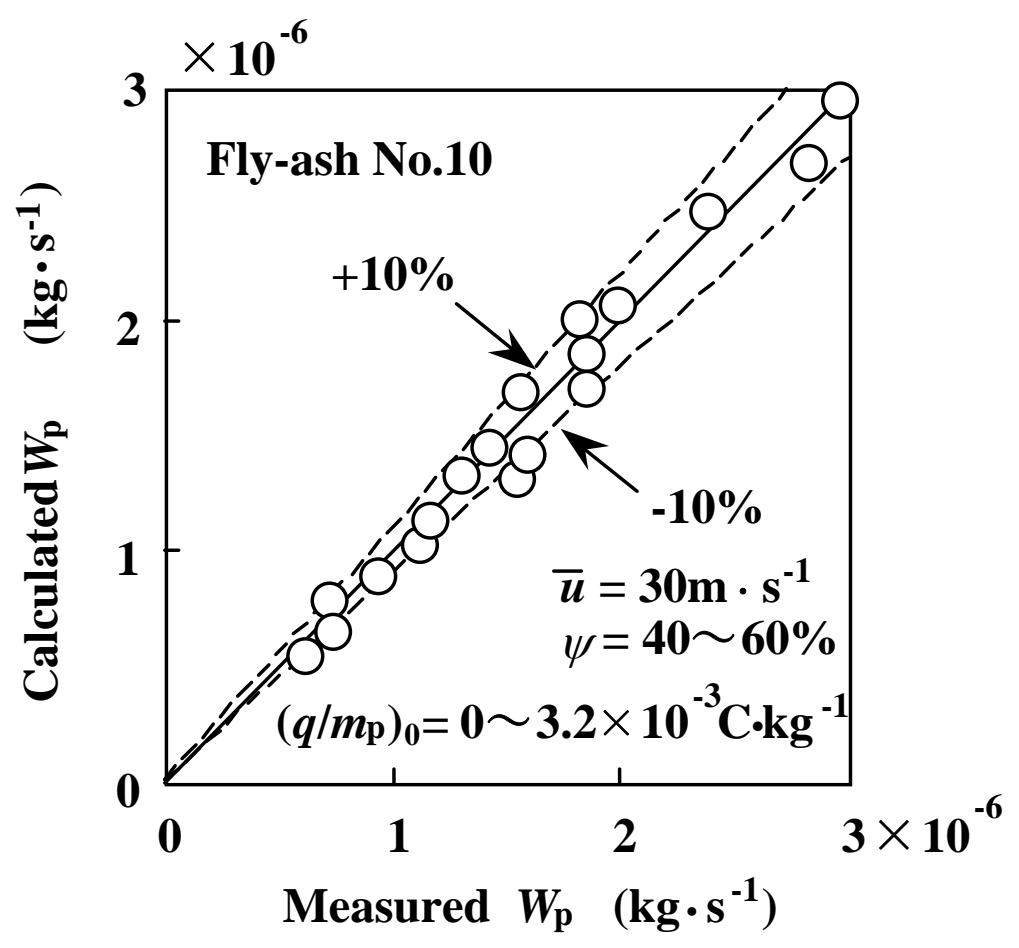

Figure 12. Comparison between calculated powder flow rate and measured value (fly-ash) 


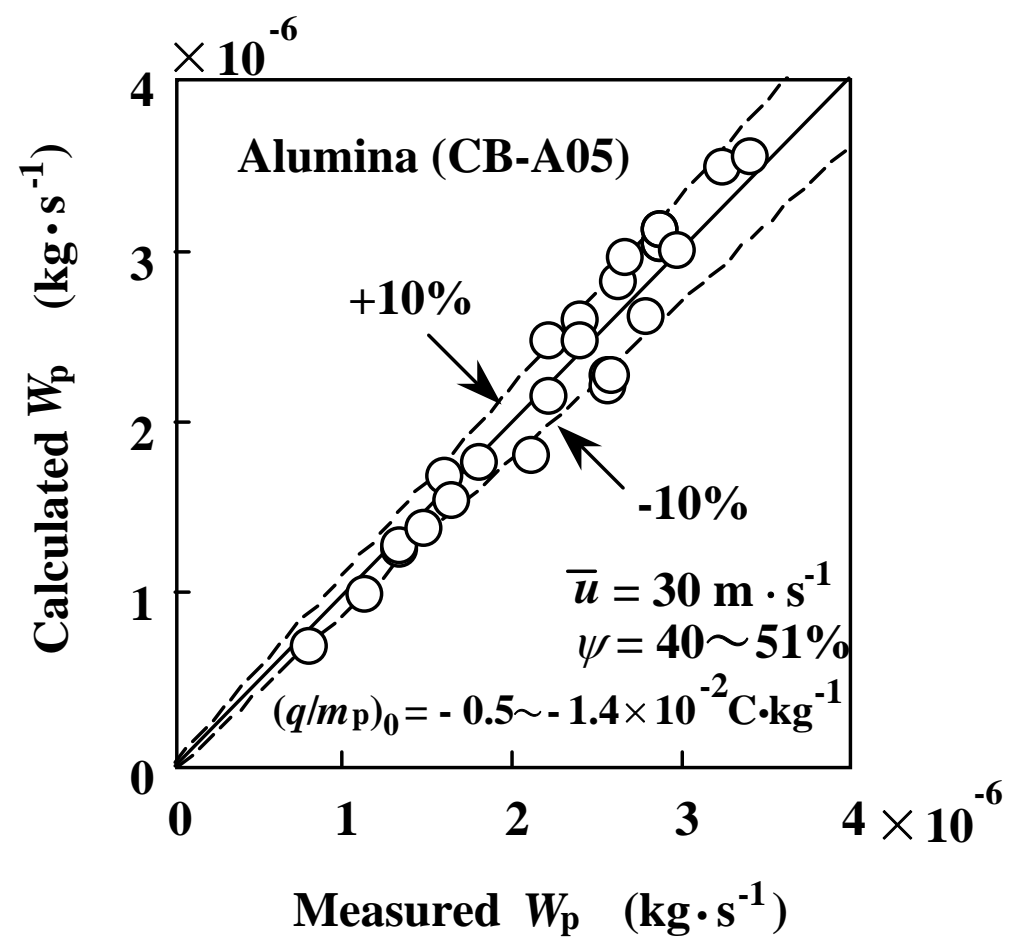

Figure 13. Comparison between calculated powder flow rate and measured value (alumina) 


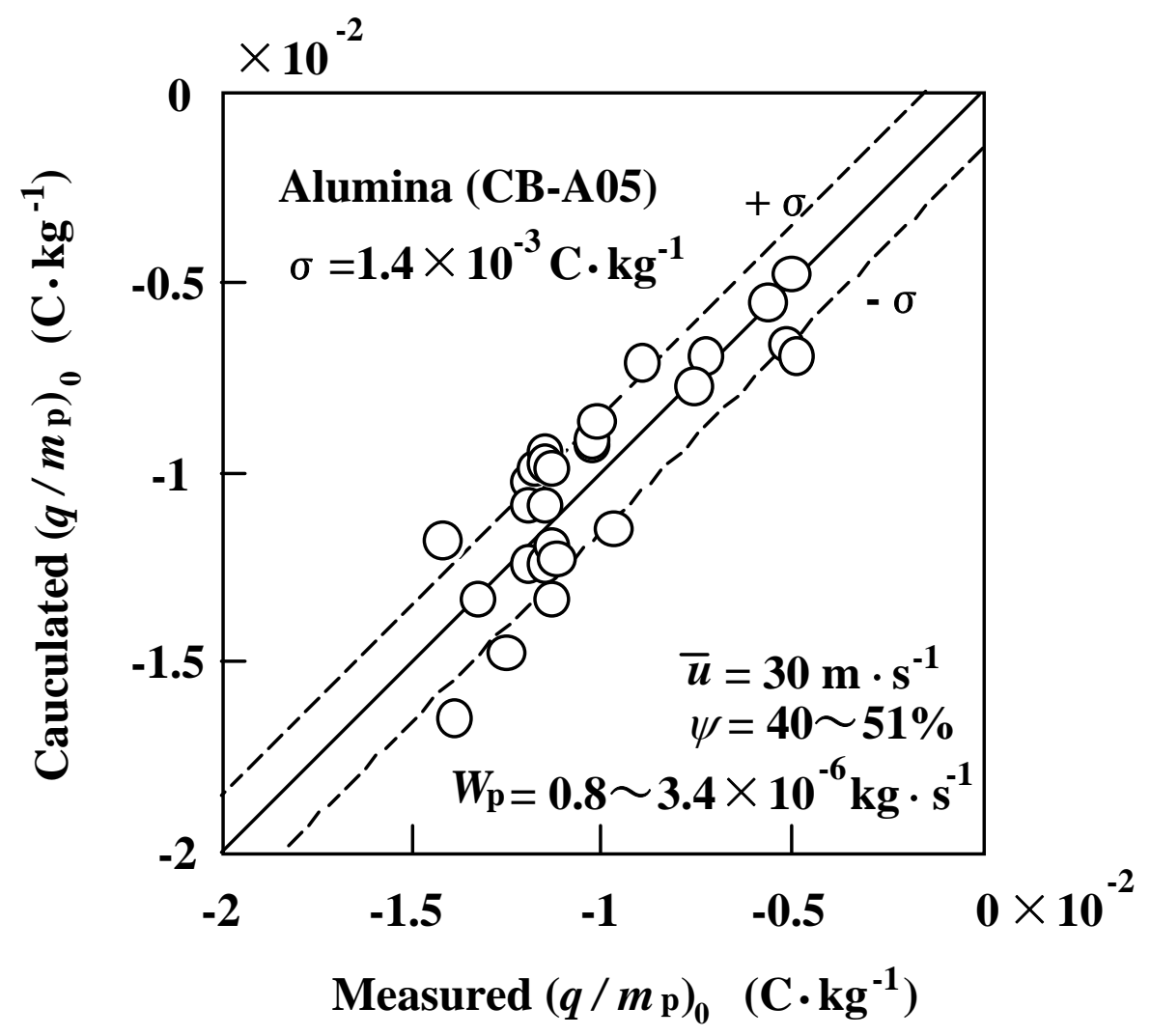

Figure 14. Comparison between calculated initial charge per unit mass of particles and measured value 
